\title{
PENGARUH INVESTASI ASET TETAP DAN BIAYA OPERASIONAL TERHADAP PENDAPATAN OPERASIONAL PADA PT. SANSHIRO HARAPAN MAKMUR
}

\section{THE INFLUENCE OF FIXED ASSETS INVESMENT AND OPERATING EXPENSES TOWARD OPERATIONAL INCOME AT PT. SANSHIRO HARAPAN MAKMUR.}

\author{
M.N. Mukmin, Gusprasetyo \\ Program Studi Akuntansi Fakultas Ekonomi Universitas Djuanda Bogor \\ Jl. Tol Ciawi No. 1, Kotak Pos 35, Kode Pos 16720, Telp/Fax : (0251) 8245155 \\ Email : mas.nur.mukmin@unida.ac.id, Gusprasetyo@unida.ac.id
}

\begin{abstract}
Research the purpose of this is to determine the influence of Fixed Assets Investment and Operating Expenses to Operating Income simultaneously and partially in PT Makmur Sanshiro expectations. This research is classified as causal research. Analysis of data using multiple linear regression. The results showed, simultaneously Fixed Asset Investment and Operating Costs Operating affect the revenue. Only partially influenced Operating Cost to Operating Income.
\end{abstract}

Keywords: Fixed Asset Investment, Operating Expenses, Operating Income

\begin{abstract}
ABSTRAK
Tujuan dari peneitian adalah untuk mengetahui pengaruh Investasi Asset Tetap dan Biaya Operasional terhadap Pendapatan Operasional pada PT.Sanshiro Harapan Makmur. Penelitian ini merupakan jenis penelitian kausal. Analisis data menggunakan regresi linear berganda. Hasil penelitian menunjukan, secara simultan Investasi Aset Tetap dan Biaya Operasional berpengaruh terhadap pendapatan Operasional. Secara parsial hanya Biaya Operasional yang berpengaruh terhadap Pendapatan Operasional.
\end{abstract}

Kata Kunci : Investasi Aset Tetap, Biaya Operasional, Pendapatan Operasional 


\section{PENDAHULUAN}

Globalisasi yang semakin kompetitif. Perusahaan-perusahaan harus mempunyai suatu tujuan agar dapat bertahan dalam waktu panjang. Disamping itu perusahaan sebaiknya dapat mengelola assetnya agar dapat menunjang aktivitas operasionalnya. Hal ini sangat penting agar tujuan perusahaan dapat tercapai kearah yang lebih baik. Dan yang perlu mendapatkan perhatian adalah pengelolaan asset perusahaan khususnya pengelolaan asset tetap perusahaan agar eksistensi perusahaan dapat tetap terpelihara.

Perusahaan dalam mencapai tujuan, harus dapat melakukan pengembangan usaha agar dapat terus dipertahankan. Untuk itu perusahaan membutuhkan manajemen yang baik, agar bisa memaksimalkan kemampuan sumber-sumber daya yang dimiliki perusahaan agar lebih efektif dan efisien, dalam memaksimalkan laba perusahaan dan menghasilkan kebijakan yang tepat agar citacita perusahaan dapat dicapai sehingga usahanya dapat lebih berkembang secara berkesinambungan. Salah satu strategi yang digunakan untuk mempertahankan usahanya perusahaan harus menambah Asset tetap,

Tabel 1. Pendapatan Operasional PT.Sanshiro Harapan Makmur 2010-2015

\begin{tabular}{|c|c|c|c|c|c|}
\hline \multirow[b]{2}{*}{ Tahun } & \multirow{2}{*}{\multicolumn{2}{|c|}{$\begin{array}{c}\text { Pendapatan Operasional } \\
\text { yang Dicapai }\end{array}$}} & \multicolumn{3}{|c|}{ Perkembangan Laba Operasional } \\
\hline & & & $\begin{array}{r}\text { Naik T } \\
0\end{array}$ & $\begin{array}{l}\text { unnya Pendapatan } \\
\text { rasional (Rp) }\end{array}$ & $\begin{array}{l}\text { Persentase Pertumbuhan } \\
\text { Pendapatan operasional }\end{array}$ \\
\hline 2010 & $\mathrm{Rp}$ & $1.381 .732 .900,00$ & & - & - \\
\hline 2011 & $\mathrm{Rp}$ & $4.212 .509 .950,00$ & $\mathrm{Rp}$ & $2.830 .777 .050,00$ & 204,87 \\
\hline 2012 & $\mathrm{Rp}$ & $4.033 .818 .584,00$ & $\mathrm{Rp}$ & $(178.691 .366,00)$ & $-4,24$ \\
\hline 2013 & $\mathrm{Rp}$ & $6.327 .831 .983,00$ & $\mathrm{Rp}$ & $2.294 .013 .399,00$ & 56,87 \\
\hline 2014 & $\mathrm{Rp}$ & $19.154 .013 .130,00$ & $\mathrm{Rp}$ & $12.826 .181 .147,00$ & 202,69 \\
\hline 2015 & $\mathrm{Rp}$ & $21.586 .634 .107,00$ & $\mathrm{Rp}$ & $2.432 .620 .977,00$ & 12,70 \\
\hline
\end{tabular}

Sumber : Laporan Keungan PT.Sanshiro Harapan Makmur data diolah 2016

Berdasarkan tabel 1, pendapatan operasional yang diperoleh dari tahun 20102015 menunjukkan fluktuasi yang cenderung naik dan hanya mengalami penurunn di tahun 2012 sebesar4,24\%. Keadaan ini menunjukan keadaan yang kurang baik. karena pendapatan tidak stabil pada tahun 2010-2015. Tabel di atas dapat kita menunjukan terdapat kenaikan yang signifikan hingga $204,87 \%$ atau sebesar Rp. 2.830.777.050 dan terjadi kenaikan kembali pada tahun 2013-2015. Kenaikan tersebut terjadi karena adanya pengembangan usaha di bidang rental mobil dan Training Education Center. Adanya pengembangan dengan harapan dapat meningkatkan laba pusahaan yang dapat digunakan perusahaan untuk menunjang kegiatan operasional. Asset tetap adalah asset yang memiliki masa manfaat $>1$ tahun serta tidak diperdagangkan dan nilainya cukup besar. Syamsudin (2007;409), aset tetap seringkali disebut sebagai "the earning assets" (asset sesungguhnya menghasilkan pendapatan bagi perusahaan) karena asset tetap inilah yang memberikan dasar bagi "earning power" perusahaan. Tanpa adanya mesin dan peralatan-peralatan lain, perusahaan tidak akan menghasilkan barang jadi.

Perusahaan dalam meningkatkan laba usaha, sebaiknya melakukan pengembangan usahanya. Tak terkecuali PT. Sanshiro Harapan Makmur yang merupakan perusahaan jasa penerjemah yang hingga kini sedang melakukan pengambangan usahanya dengan cara membuka usaha Kursus Bahasa Jepang dan Rental Kendaraan dengan harapan pengembangan ini dapat meningkatkan laba perusahaan. Data dibawah ini merupakan perolehan pendapatan operasional PT.Sanshiro Harapan Makmur, selama Periode 2010 sampai 2015 antara lain:
Perkembangan Laba Operasional 
membuat pendapatan perusahaan berkurang. Untuk menutupi fixed cost perusahan harus mampu memaksimalkan asset tetap yang sudah dimilikinya agar mendapatkan pendapatan sebesar-besarnya. Tetapi pada pelaksanaannya tidak semua kendaraan digunakan secara maksimal, khususnya kendaraan-kendaraan kelas Premium seperti Alphard, Camry, Accord dll yang banyak standby dari pada beroperasi. Biaya investasi yang diperlukan untuk kendaraan tersebut tidak kecil di tambah biaya penyusutan dan biaya pemeliharaan yang menjadi beban perusahaan di setiap bulannya, yang membuat berkurangnya pendapatan operasional perusahaan.

Perusahaan untuk meningkatkan pendapatan operasional, telah menambah investasi asset agar perusahaan dapat tetap terjaga dan lebih mengefisienkan biaya operasional (cost) yang dikeluarkan perusahaan. Dengan ketentuan pendapatan operasional tetap dapat lebih ditingkatkan. Semakin kecil biaya dan semakin besar pendaptan maka laba yang dihasilkan akan semakin besar. Apabila investasi asset tetap melebihi yang diperlukan oleh perusahaan maka fixed cost akan semakin besar bagi perusahaan. Sebaliknya jika investasi asset tetap terlalu kecil mengakibatkan perusahaan kehilangan sebagian besar pasar. Karena itu perusahaan harus melakukan investasi asset tetap secara cermat dan tepat. Karena investasi asset tetap biasanya merupakan suatu Komitmen jangka panjang (LongTerm Financing) dan menghasilkan pendapatan dalam waktu yang lama dan berkelanjutan. Tujuan yang hendak dicapai dari penelitian ini yaitu untuk mengetahuii pengaruh investasi asset tetap dan biiaya operasional terhadap pendpatan operasional pada PT. Sanshiro Harapan Makmur, dan pengaruh investasi asset tetap dan Biaya Operasional secara parrsial terhadap pendapatan.

\section{METODE PENELITIAN}

Desain dalam penelitian iniadalah penelitian Kausal yang dilakukan untuk memperoleh gambaran tentang pengaruh Invstasi Asset tetap dan Biaya Operasional terhadap pendaatan operasional pada PT.Sanshiro Harapan Makmur. Populasi dalam penelitian ini adalah seluruh investasi asset tetap dan biaya operasional pada PT. Sanshiro
Harapan Makmur dan untuk sampel yang di ambil adalah investasi asset tetap dan biaya operasional untuk tahun 2010-2015 pada PT. Sanshiro Harapan Makmur. Objek dalam penelitian ini adalah Investasi Asset Tetap dan Biaya Operasional. Data Primer penelitian ini berupa laporan keuangan tahunan, data biaya operasional perusahaan, dan perkembangan Asset tetap. Data Sekunder didapat dengan cara menelaah data yg ada di PT.Sanshiro Harapan Makmur serta literatur-literatur yang berhubungan dengan maslah yang dianalisis.

\section{Analisis Data}

Teknik analisis data dalam penelitian kuantitatif menggunakan alat statistik. Dalam penelitian ini variabel yang diteliti terdiri dari 2 variabel, yaitu variabel bebas dan variabel terikat, Investasi Aset $\operatorname{Tetap}\left(\mathrm{X}_{1}\right)$ dan Biaya operasional $\left(\mathrm{X}_{2}\right)$ merupakan variabel bebas sedangkan variabel terikat adalah Pendapatan operasional (Y). Analisis yang digunakan adalah analisis regresi berganda dengan pengujian data menggunakan metode asumsi klasik, dan untuk mengetahui pengaruh Aset $\operatorname{Tetap}\left(\mathrm{X}_{1}\right)$ dan Biaya operasional $\left(\mathrm{X}_{2}\right)$ terhadap Pendapatan operasional (Y) dengan menggunakan pengujian hipotesis.

\section{Persamaan Regresi Linier Berganda}

Analisis regresi dipakai untuk menetapka bentuk (dari) hubungan antar variabel. Iqbal Hasan (2008:220), tujuan utama dalam penggunaan analisis itu adalah "untuk meramalkan atau memperkirakan nilai dari satu variael dalam hubungannya dengan variabel yg lain yang diketahui melalui persamaan garisregresinya".

\section{Pengujian Hipotesis secara Serentak}

Pengujian hipotesis secara serentak merupkan pengujian hipotesi koefisien regresi berganda dengan $X_{1}$ dan $X_{2}$ secara serentak dalam mempengaruhi $Y$. untuk menguji hipotesis secara serentak, dapat diuji dengan rumus uji F. uji F bermasksud untuk menguji ada atau tidak pengruh variabel independen $\left(\mathrm{X}_{1}\right.$ dan $\left.\mathrm{X}_{2}\right)$ terhadap variabel dependen( $\left.\mathrm{Y}\right)$ secara serentak.

Mengambil kesimpulan :

1. Bila $F$ hitung $>\mathrm{F}$ tabel, makaHo ditolak (hubungan $\mathrm{X}_{1}, \mathrm{X}_{2} \ldots . \mathrm{Xn}$ denganY adalah signifikan) 
2. Bila $F$ Hitung $\leq$ Ftabel, maka $H_{1}$ ditolak (hubungan $\mathrm{X}_{1}, \mathrm{X}_{2} \ldots \mathrm{Xn}$ dengan $\mathrm{Y}$ adalah tidak signifikan)

\section{Pengujian Hipotesis secara Parsial}

Pengujian hipotesis secara parsial, dapat diuji dengan rumus uji t. pengujian t-statistik bermaksud untuk menguji ada atau tidaknnya pengaruh masing-masing variabel independen $\left(\mathrm{X}_{1}\right.$ atau $\left.\mathrm{X}_{2}\right)$ terhadap variabel dependen $(\mathrm{Y})$. Pengambilan kesimpulan dengan ketentuan :

1. Bila t hitung $\geq \mathrm{t}$ tabel, pada $a=0,05$ maka $\mathrm{H}_{0}$ ditolak dan $\mathrm{H}_{1}$ diterima (hubungan $\mathrm{X}_{\mathrm{n}}$, dengan $Y$ adalah signifikan)

2. Bila t hitung $\leq \mathrm{t}$ tabel, maka $\mathrm{H}^{1}$ ditolak dan $\mathrm{H}_{0}$ diterima (hubungan $\mathrm{X}_{\mathrm{n}}$, denganY adalah tidak signifikan)

\section{Koefisien Determinasi $\left(\mathbf{R}^{2}\right)$}

Koefisien determinasi $\left(\mathrm{R}^{2}\right)$ merujuk kepada kemampuan dari variabel independen $(\mathrm{X})$ dala menerangkan variabel dependen (Y) yang memperlihatkan persentase variasi variable $\mathrm{X}$ akan mempengaruhi variabel $\mathrm{Y}$. Sudjana, (2004:246) nilai $K_{d}$ berada antara 0sampai1 $\left(0 \leq \mathrm{K}_{\mathrm{d}} \leq 1\right)$ dengan ketentuan :

a. Jika nilai $K_{d}=0$ berarti tidak ada pengaruh variable $\mathrm{x}$ terhadap variabel $\mathrm{Y}$.

Tabel 2. Perhitungan Investasi Aset Tetap PT.Sanshiro Harapan Makmur Tahun 2010-2015

\begin{tabular}{rrrr}
\hline \multirow{2}{*}{ Tahun } & Investasi aktiva Tetap $\left(X_{1}\right)$ & Perkembangan & \\
& & & $(\%)$ \\
2010 & $13,232,350$ & 0 & 0 \\
2011 & $532,960,500$ & $519,728,150$ & 3927.71 \\
2012 & $547,395,280$ & $14,434,780$ & 2.71 \\
2013 & $1,017,572,860$ & $470,177,580$ & 85.89 \\
2014 & $6,414,272,555$ & $5,396,699,695$ & 530.35 \\
2015 & $2,559,280,291$ & $(3,854,992,264)$ & $(60.10)$ \\
\hline
\end{tabular}

Sumber : Laporan Inventaris PT.Sanshiro Harapan Makmur, diolah 2016

Berdasarkan tabel 2. diatas diketahui bahwa investasi asset tetap PT.Sanshiro Harapan Makmur tahun 2010-2015 mengalami fluktuasi namun cenderung mengalami kenaikan.

\section{Perkembangan Biaya Operasional di PT. Sanshiro Harapan Makmur}

Tujuan setiap perusahaan adalah menghasilkan pendapatan sebesar - besarnya dengan pengeluaran sekecil-kecilnya. Untuk b. Jika nilai $K_{d}=1$ berarti variasi (naik turunnya) variabel dependen $\mathrm{Y}$ adalah $100 \%$ dipengaruhi oleh variable independen (variabel X)

c. Jika nilai $K_{d}$ berada antara0 samapai $1(0 \leq$ $\mathrm{K}_{\mathrm{d}} \leq 1$ ) maka besarnya pengaruh variabelindependen adalah sesuai dengan nilai $K_{d}$ itusendiri atau sebaliknya berasal dari faktor-faktor yang lain

\section{HASIL DAN PEMBAHASAN}

\section{Perkembangan Investasi Asset Tetap di PT.Sanshiro Harapan Makmur}

Investasi dalam asset tetap merupakan bagian yang tak terlepaskan dari pelaksanaan kegiatan operasional perusahaan, dan merupakan harapan perusahaan untuk memproleh kembali dana yang telah diinvestasikan dalam aset tetap tersebut. Investasi asset tetap berupa penanaman modal, dilakukan oleh prusahaan dengn harapan bahwa suatu saat kegiatan operasional perusahaan tersebut dapat menghasilkan laba maksimal dari hasil investasinya. Artinya investasi tersebut harus dikelola dengan baik agar dapat memberikan keuntngan bagi perusahaan. Berdasarkan laporan keuangan pada tahun 2010-2015 terdapat gambaran investasi asset tetap pada PT. Sanshiro Harapan Makmur. 
dari PT. Sanshiro Harapan Makmur tentang

bawah ini :

biaya operasional dapat seperti pada tabel di

Tabel 3. Perkembangan Biaya Operasional PT. Sanshiro Harapan Makmur Tahun 2010-2015

\begin{tabular}{cccc}
\hline \multirow{2}{*}{ Tahun } & Biaya Operasional $(\mathrm{x} 2)$ & \multicolumn{2}{c}{ Perkembangan } \\
& & $(\mathrm{Rp})$ & $(\%)$ \\
\hline 2010 & $492,994,488$ & 0 & 0 \\
\hline 2011 & $4,101,702,100$ & $3,608,707,612$ & 732.00 \\
2012 & $5,520,589,435$ & $1,418,887,335$ & 34.59 \\
2013 & $8,849,143,257$ & $3,328,553,822$ & 60.29 \\
2014 & $17,355,621,369$ & $8,506,478,112$ & 96.13 \\
2015 & $18,604,955,619$ & $1,249,334,250$ & 7.20 \\
\hline
\end{tabular}

Sumber : Laporan Keuangan PT.Sanshiro Harapan Makmur, diolah 2016

Berdasarkan tabel tersebut

menggambarkan perkembangan biaya

operasional di PT. Sanshiro Harapan Makmur

dari periode 2010-2015 senantiasa mengalami

kenaikkan kearah yang positif dan lebih baik.

\section{Perkembangan Pendapatan Operasional di PT.Sanshiro Harapan Makmur}

Telah dikemukakan sebelumnya dimana pendapatan operasional merupakan hasil dari

aktivitas perusahaan berupa penjualan jasa oleh perusahaan kepada customer. PT. Sanshiro Harapan Makmur mendapatkan pendapatan Operasional dari berbagai jasa yang diberikan, mulai dari Jasa Penerjemah Bahasa Jepang (Interpreter), Rental kendaraan dan Pelatihan Bahasa Jepang. Adapun data perkembangan pendapatan operasional pada PT. Sanshiro Harapan Makmur sebagai berikut

Tabel 4. Perkembangan Pendapatan Operasional PT. Sanshiro Harapan Makmur Tahun 2010-2015

\begin{tabular}{ccrc}
\hline \multirow{2}{*}{ Tahun } & Pendapatan Operasional $(\mathrm{Y})$ & \multicolumn{2}{c}{ Perkembangan Laba Operasional } \\
& & $(\mathrm{Rp})$ & - \\
\hline 2010 & 1.381 .732 .900 & - & 204,87 \\
2011 & 4.212 .509 .950 & 2.830 .777 .050 & $(4,24)$ \\
2012 & 4.033 .818 .584 & $(178.691 .366)$ & 56,87 \\
2013 & 6.327 .831 .983 & 2.294 .013 .399 & 202,69 \\
2014 & 19.154 .013 .130 & 12.826 .181 .147 & 12,70 \\
2015 & 21.586 .634 .107 & 2.432 .620 .977 & \\
\hline
\end{tabular}

Sumber : Laporan keuangan PT.Sanshiro Harapan Makmur, diolah 2016

Tabel 4. menunjukkan bahwa berdistribusi normal. Dan dengan Normal Pperkembangan pendapatan operasional PT. Sanshiro Harapan Makmur pada periode 20102015 mengalami fluktuasi yang kearah yang positif dan hanya turun pada tahun 2012, $4,24 \%$. Keadaan ini menunjukan keadaan yang kurang baik. Karena pendapatan tidak stabil pada tahun yang diteliti.

\section{Uji Normalitas}

Dari hasil Kolmogorov-Smirnov Test menunjukan bahwa nilai sig sebesar 0,998 yang berarti $>0,05$ yang menunjukan data berdistribusi normal. Dapat diambil kesimpulan dimana model regresi telah memadai untuk diijadikan model regresi dengan hasil baik. Analisa data menghasilkan Grafik histogram yang membentuk bel, maka kesimpulannya adalah data sampel

Plot of Regression Standarized Residual dapat ditarik kesimpulan grafik normal plot, dimana terlihat sebaran titik-titik dekat garis diagonal. Hal tersebut mengindikasikan bahwa regresi dapat dijadikan sebagai model regresi, sebab model regresi Mempunyai distribusi data normal dan/atau mendekati normal.

\section{Uji Autokorelasi}

Ada tidaknya suatu autokorelasi dapat dilakukan melalui uji run test. Artinya dengan run test kita dapat melihat residual terjadi random atau tidak. Pengujian menunjukan nilai Asymp.Sig. (2-tailed) > 0.05 yang berarti data yang dipegunakan cukup random.

\section{Uji Heteroskedastisitas}


Pada sumbuY titik-titik menyebar secaraacak di atas maupun dibawah angka nol. Karena model homoskedastisitas atau varians dari residual pengamatan satu ke pengamatan yang lain tetap, maka disimpulkan bahwa model ini menjadi model yang baik.

\section{Uji Multikolinieritas}

Dari Uji Multikolinieritas, hasil perhitungan yang diperoleh tolerance value sebesar 0,341 dan nilai VIF 2,933. Kesimpulannya bahwa pada variable bebas tidak terjadi multikolinieritas.

\section{Analisis Korelasi Berganda}

Hasil perhitungan koefisien korelasi berganda (R) adalah sebesar 0,980. Artinya keeratan hubungan antara Investasi Asset tetap danbiaya operasional terhadap pendapatan operasional termasuk kriteria sangat kuat dan menunjukan hubungannya positif. Artinya apabila Investasi Asset Tetap dan Biaya Operasional mengalami peningkatan, maka Pendapatan Operasional juga akan mengalami peningkatan, dan begitu pun sebaliknya.

\section{Analisis Regresi Berganda}

Perhitungan statistic menunjukkan adanya persamaan regresi berganda antara variabel Investasi Asset Tetap (X1) dan Biaya Operasional (X2) terhadap Pendapatan Operasional (Y).

Tabel 5. Coefficients ${ }^{a}$

\begin{tabular}{|c|c|c|c|c|c|}
\hline \multirow[b]{2}{*}{ Model } & \multicolumn{2}{|c|}{ Unstandardized Coefficients } & \multirow{2}{*}{$\begin{array}{l}\text { Standardized } \\
\text { Coefficients } \\
\text { Beta }\end{array}$} & \multirow[b]{2}{*}{$\mathrm{t}$} & \multirow[b]{2}{*}{ Sig. } \\
\hline & $B$ & Std. Error & & & \\
\hline (Constant) & -983268509.9 & 1570561342.995 & & -.626 & .576 \\
\hline $1 \mathrm{X} 1$ & .179 & .701 & .050 & .255 & .815 \\
\hline $\mathrm{X} 2$ & 1.104 & .229 & .940 & 4.821 & .017 \\
\hline
\end{tabular}

a. Dependent Variable: Pendapatan Operasional Sumber : SPSS Statistics 20, diolah 2016

Berdasarkan pada Tabel 5. Di atas memperlihatkan persamaan regresi sebagai berikut:

$$
\begin{aligned}
& Y=a+b_{1} X_{1}+b_{2} X_{2} \\
& Y=-983268509,983+0,179 X_{1}+1,104 X_{2}
\end{aligned}
$$

Hasil dari masing-masing variabel dapat diinterpretasikan hubungannya sebagai berikut:

1. Investasi Asset Tetap memiliki nilai koefisien regresi berganda positif sebesar 0,179 . Artinya apabila nilai koefisienregresi lainnya tetap, maka akan menambah Investasi Asset Tetap sebesar satu rupiah dan dapat meningkatkan pendpatan operasional sebesar 0.179 rupiah.
2. Sedangkan biayaoperasional memiliki nilai positif sebesar 1.104 rupiah dengan asumsi nilai koefisien regresi lainnya tetap, maka perubahan nilai sebesar satu rupiah akan menaikkan pendapatan operasional sebesar 1.104 rupiah.

\section{Analisisa Koefisien Determinasi}

Dengan uji ini diharapkan dapat diketahui besarnya pengaruh variabel $X_{1}$ dan $\mathrm{X}_{2}$ terhadap Y Pendapatan Operasional pada PT. Sanshiro Harapan Makmur. Dengan menggunakan SPSS, diperoleh koefisien determinasi seperti pada tabel output di bawah ini.

Tabel 6. Model Summary

\begin{tabular}{ccccr}
\hline Model & $R$ & $R$ Square & Adjusted R Square & Std. Error of the Estimate \\
\hline 1 & $.980^{\mathrm{a}}$ & .961 & .935 & 2197830623.613 \\
\hline
\end{tabular}

a. Predictors: (Constant), Beban Operasional, Investasi Aktiva tetap

Sumber : SPSS Statistics 20, diolah 2016

Dengan mengunakan SPSS dapat diperoleh koefisien determinasi sebesar 0,961. Ini berarti bahwa Investasi Asset Tetap dan Biaya Operasional mempengaruhi tingkat Pendapatan Operasional secara simultan dari tahun 2010-2015 sebesar 96,1\%, sisanya
$3,9 \%$ dipengaruhi oleh faktor-faktor yang tidak diteliti.

\section{Uji F}

Untuk mengetahui apakah ada pengaruh antara Investasi Asset dengan Biaya 
Operasional pada PT. Sanshiro Harapan Makmur dengan merumuskan hipotesis statistic berikut ini :

$\mathrm{H}_{\mathrm{o}}: \mathrm{b}_{1}=\mathrm{b}_{2}=0$, Membuktikan tidakada pengaruh yg signifikan antara Variabel Investasi Asset dengan Biaya Operasional terhadap pendapatan PT. Sanshiro Harapan Makmur
$\mathrm{H}_{1}: \mathrm{b}_{1} \neq \mathrm{b}_{2}=0$, terdapat pengaruh antara variabel Investasi Asset Tetap dengan Biaya Operasional dan mempengaruhi secara simultan terhadap Pendapatan PT. Sanshiro Harapan Makmur

Tabel 7. ANOVA ${ }^{a}$

\begin{tabular}{cccccc}
\hline Model & Sum of Squares & $d f$ & Mean Square & $F$ & Sig. \\
\hline 1 Regression & $3.586 \mathrm{E}+20$ & 2 & $1.793+20$ & 37.117 & $.008^{\mathrm{b}}$ \\
Residual & $1.449 \mathrm{E}+19$ & 3 & $4.830 \mathrm{E}+18$ & & \\
& $3.731 \mathrm{E}+20$ & 5 & & &
\end{tabular}

a. Dependent Variable: Pendapatan Operasional

b. Predictors: (Constant), Beban Pendapatan, Investasi Asset tetap Sumber : data diolah 2016

Berdasarkan Tabel 7. di atas memperlihatkan bahwa perbandingan $\mathrm{F}_{\text {hitung }}$ dan $\mathrm{F}_{\text {tabel }}$ adalah $\mathrm{H}_{0}$ ditolak dan $\mathrm{H}_{1}$ dapat diterima, karena $F_{\text {hitung }}(37,117) \geq F_{\text {tabel }}(4,26)$, sehingga diperoleh pengaruh yang signifikan dan simultan antara Investasi Asset Tetap dan
Biaya Operasional terhadap Pendapatan PT. Sanshiro Harapan Makmur.

Uji t

Dari uji t didapat hasil pengujian untuk pengaruh Investasi Asset Tetap dan Biaya Operasional terhadap Pendapatan PT. Sanshiro Harapan Makmur seperti pada tabel 8.

Tabel 8. Tabel Coefficients ${ }^{a}$

\begin{tabular}{|c|c|c|c|c|c|}
\hline \multirow{2}{*}{ Model } & \multicolumn{2}{|c|}{ Unstandardized Coefficients } & Standardized & \multirow{2}{*}{$\mathrm{t}$} & \multirow{2}{*}{ Sig. } \\
\hline & $B$ & Std Frror & Reta & & \\
\hline (Constant) & -983268509.9 & 1570561342.995 & & -.626 & .576 \\
\hline $1 \mathrm{X} 1$ & .179 & .701 & .050 & .255 & .815 \\
\hline $\mathrm{X} 2$ & 1.104 & .229 & .940 & 4.821 & .017 \\
\hline
\end{tabular}

a. Dependent Variable: Pendapatan Operasional

Sumber : SPSS Statistics 20, diolah 2016

\section{Pengaruh Investasi Asset Tetap Terhadap Pendapatan Operasional}

Untuk mengetahui signifikansi pengaruh antara Investasi Asset Tetap $\left(\mathrm{X}_{1}\right)$ terhadap Pendapatan Operasional $(\mathrm{Y})$ secara signifikan, harus dilakukan uji hipotesis statistic sebagai berikut:

Ho : $b_{1}=0$, Hasil uji memperlihatkan tidak adanya pengaruh yang signifikan secara parsial antara Investasi Asset Tetap (X1) pada Pendapatan Operasional PT. Sanshiro Harapan Makmur.

$\mathrm{H}_{1}: \mathrm{b}_{1} \neq 0$, Hasil uji menunjukkan adanya pengaruh yang signifikan secara parsial antara Investasi Asset Tetap $\left(\mathrm{X}_{1}\right)$, terhadap Pendapatan Operasional (Y) PT. Sanshiro Harapan Makmur.
Dari Tabel 4.11, diperoleh $t_{\text {hitung }}$ sebesar $0,255<t_{\text {tabel }}$ sebesar 2,228 dan tingkat signifikansi sebesar $0,815>\alpha=0,05$, maka $\mathrm{H}_{0}$ diterima, artinya tidak terdapat pengaruh yang signifkan secara parsial antara Investasi Asset Tetap terhadap Pendapatan Operasional di PT. Sanshiro Harapan Makmur.

\section{Pengaruh Biaya Operasional Terhadap Pendapatan Operasional}

Untuk mengetahui signifikansi pengaruh antara $\left(\mathrm{X}_{2}\right)$ terhadap $(\mathrm{Y})$, maka perlu dilakukan uji hipotesis statistic sebagai berikut:

Ho : $b_{1}=0$, Berdasarkan hasil pengujian tidak ada pengaruh yang signifikanantara (X2) dengan (Y) di PT.Sanshiro Harapan Makmur 
$\mathrm{H}_{1}: \mathrm{b}_{1} \neq 0$, Hasil pengujian menunjukkan adanyapengaruh (2) terhadap (Y) di PT.Sanshiro Harapan Makmur

Tabel 8. diperoleh $t_{\text {hitung }}$ sebesar 4,821 < $t_{\text {tabel }}$ sebesar 2,228 dan tingkt signifikansi sebesar $0,017<\alpha=0,05$, maka $\mathrm{H}_{0}$ ditolak, berarti terdapat pengaruh yang signifikan secara parsial antara Biaya Operasional terhadap Pendapatan Operasional di PT. Sanshiro Harapan Makmur.

\section{Kesimpulan}

Berdasarkan hasil pembahasan dan penelitian dapat disimpulkan bahwa:

1. Investasi asset tetap dan biaya operasional berpengaruh secara simultan terhadap pendapatan operasional pada PT. Sanshiro Harapan Makmur.

2. Tidak terdapat pengaruh yang signifikan secara parsial investasi asset tetap terhadap Pendapatan opersional pada PT. Sanshiro Harapan Makmur, karena investasi terhadap asset tetap tidak dignakan secara optimal.

3. Terdapat pengaruh yang signifkan secara parsial biaya opersional terhadap pendapatan opersional pada PT. Sanshiro Harapan Makmur.

\section{Daftar Pustaka}

Ernawati, Francisca, 2015, Pengaruh Biaya Operasional Terhadap Laba Bersih Dengan Perputaran Persediaan Sebagai Variabel Pemoderasi, Jurnal Ilmiah dan Riset Manajemen Volume 4, Nomer 9, Agustus 2015.

Kartadireja Atep, 2009, Pengaruh Investasi Aktiva Tetap Terhadap Pendapatan Operasional Perusahaan (Studi kasus pada PT. Indo Bharat Rayon Purwakarta), Skripsi FE Universitas Widyatama

Ikatan Akuntansi Indonesia, 2011, Pernyataan Standar Akuntansi Keuangan (PSAK), Jakarta

Irwansyah, 2014, Efektivitas Dan Kontribusi Pajak Hotel Terhadap Pendapatan
Asli Daerah (Studi di Pemerintah Daerah Kota Semarang), Skripsi Fakultas Ekonomika dan Bisnis Universitas Diponegoro

Munawir, S, 2007, Analisis Laporan Keuangan (Edisi Keempat), Yogyakarta, Liberty

Nugroho,W, 2006, Investasi Aktiva Tetap Terhadap Pendapatan Operasional Perusahaan (Studi Kasus Pada PT Kereta Api Bandung), Skripsi Sarjana Fakultas Ekonomi Universitas Widyatama

Sandika, Maulida, Setiawan, Pengaruh Investasi Terhadap Penyerapan Tenaga Kerja di Kabupaten Pelawan, JOM FEKON1. NO. 2 OKTOBER 2014

Sugiyono, 2015, Metode Penelitian Kuantitatif, Kualitatif, Dan R\&D Penerbit Alfabeta, Bandung

Soemarso S,R, 2009, Akuntansi Suatu Pengantar, Edisi 5, Jakarta: Salemba Empat,

Siregar, Sofian, 2010, Statistik Deskriptif Untuk Penelitian, PT, Raja Grafindo Persada, Jakarta

Saefudin, Agung Gunawan, 2013, Pengaruh Biaya Operasional Terhadap Laba (Studi Kasus pada Perusahaan Daerah Air Minum Kabupaten Purwakarta Periode Tahun 20062010), Skripsi Sarjana, Universitas Pendidikan Indonesia

Tiaradiani Santi, 2012, Pengaruh Biaya Operasional Terhadap Perolehan Laba Operasional (Studi kasus PT Bank CIMB Niaga Tbk), Skripsi Fakultas Bisnis dan Manajemen Universitas Widyatama

Warren, Fees and Reeve, 2008, Accounting, Alih bahasa: Alfonsus Sirait, Helda Gunawan, dan Erlangga, Jakarta, 